\title{
Twenty-four-hour venoarterial extracorporeal membrane oxygenation without systemic heparinization in dogs
}

Accepted: 16 November 1995

\begin{abstract}
Venoarterial extracorporeal membrane oxygenation (ECMO) was performed in five dogs without systemic heparinization to assess the feasibility of heparin-free ECMO. The surfaces of the inverted hollow-fiber-type oxygenator and circuit of the ECMO system were coated with heparin by the endpoint-attached (covalent-bonded) technique. No heparin was administered to the animal except for a small dose to maintain patency of the arterial line $(1 \mathrm{IU} / \mathrm{h})$. ECMO was run for $24 \mathrm{~h}$ at a pump flow of $50 \mathrm{ml} / \mathrm{kg} \cdot \min$ and was successful throughout the experiment in four of the five dogs. Scanning electron microscopy did not detect any blood clots in the oxygenator or circuit except for inside and outside the cannulas that were not coated with heparin in the carotid artery and jugular vein. Activated clotting time (ACT), fibrinogen, and antithrombin III (AT-III) activity remained within the normal physiological range. Serum heparin concentrations were low throughout the experiment, indicating minimal heparin release. Platelet levels decreased and fibrinopeptide $B \quad \beta 15$ 42 (FPB $\beta 15-42$ ) increased significantly after $6 \mathrm{~h}$ ECMO. D-dimer levels did not change throughout the experiment. ECMO was discontinued in one case after successful a 23-h run because of macroscopic clot formation at the oxygenator blood inlet. ACT had suddenly increased to $160 \mathrm{~s}$ approximately $1 \mathrm{~h}$ prior to this clot formation. These results suggest that the amount of systemic heparinization required can be substantially reduced by a heparin-coated ECMO system. Total abolishment of heparin administration in pediatric venoarterial ECMO may be possible by refinement of this technique. Monitoring of AT-MI and FPB $\beta 15$ 42 in addition to ACT may be useful for early diagnosis of latent but ongoing coagulopathies during ECMO.
\end{abstract}

K. Miyasaka ( $\mathbf{Z}) \cdot$ M. Takata $\cdot$ R. Muto $\cdot$ K. Miyasaka Pathophysiology Research Laboratory, National Children's Medical Research Center 3-35-31 Taishido, Setagaya, Tokyo 154, Japan

K. Miyasaka - M. Takata · R. Muto • K. Miyasaka Department of Anesthesia and Intensive Care, National Children's Hospital, Tokyo, Japan
Key words Extracorporeal membrane oxygenation • Heparin-free - Veno-arterial - Pediatrics - Critical care

\section{Introduction}

The main cause of unsuccessful treatment with extracorporeal membrane oxygenation (ECMO) has been the tendency for bleeding to occur during systemic heparinization $[10,11,17,22]$. Intracranial hemorrhage is the most serious complication and is the limiting factor for the application of ECMO in premature infants $[2,5,25]$. Uncontrollable bleeding from surgical wounds may occur when ECMO is used following trans-mediastinal operations requiring cardiopulmonary bypass. Coating the surface of the circuit with heparin may provide adequate thromboresistance to the ECMO system, thus reducing the amount of systemic heparin administration required.

Several studies $[12,20]$ have reported encouraging results with a venovenous heparin-coated ECMO system in sheep and dogs without systemic heparinization. This study was performed to assess the feasibility of systemic "heparin-free" ECMO for pediatric and neonatal treatment of respiratory failure. A neonatal venoarterial (VA) ECMO system coated with covalent-bonded heparin was used and long-term use of this system without systemic heparinization was evaluated in canine experiments.

\section{Materials and methods}

The experimental design of this study was approved by the Institutional Animal Care and Use Committee. Five beagles weighing $6.5-10.0 \mathrm{~kg}$ were placed on VA ECMO for $24 \mathrm{~h}$ at a pump flow of $50 \mathrm{ml} / \mathrm{kg} \cdot \min$. No heparin was administered to the animal except for a small dose to maintain an arterial line open $(1 \mathrm{IU} / \mathrm{h})$ during ECMO.

The dogs were anesthetized with pentobarbital sodium $(30 \mathrm{mg} / \mathrm{kg}$ IV), tracheally intubated, and ventilated with a pressure-preset, timecycled ventilator (Newport E100, NMI, CA). Anesthesia was maintained with continuous IV infusions of pancuronium bromide and ketamine hydrochloride (both $2 \mathrm{mg} / \mathrm{kg} \cdot \mathrm{h}$ ). Ventilator settings were adjusted to maintain arterial blood gases within the normal range. 


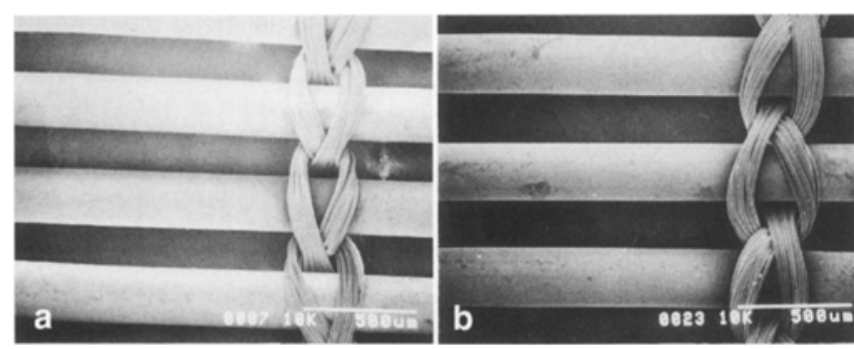

Fig. 1a-c Scanning electron photomicrograph in a successful case: hollow fibers at a inlet, b central area, and c outlet of membrane oxygenator

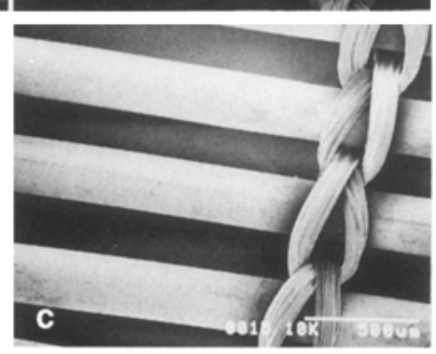

A large-bore catheter was placed in the femoral vein for blood sampling and providing maintenance fluids. A polyethylene catheter was advanced via the femoral artery into the thoracic aorta for measurement of arterial blood pressure and blood gas sampling. Penicillin $\mathrm{G}$ was given as a prophylactic both before and $12 \mathrm{~h}$ after surgical manipulation. A 12 or $14 \mathrm{~F}$ wire-reinforced, thin-wall cannula of segmented polyurethane (TW-8-12, Kuraray, Osaka, Japan) was inserted into the right jugular vein and advanced to the level of the right atrium to provide venous drainage. An $8 \mathrm{~F}$ wire-reinforced, thinwall, segmented polyurethane cannula was inserted into the right carotid artery and advanced to the level of the aortic arch to deliver oxygenated blood.

A miniaturized VA ECMO system specifically developed for neonates was used. It consists of a 2,000 $\mathrm{cm}^{2}$ double-layer polyolefin inverted, hollow-fiber membrane oxygenator (KM7800, Kuraray, Osaka, Japan) and segmented polyurethane tubing attached by polycarbonate connectors. The membrane oxygenator and tubing were coated with heparin using an end-point-attached, covalent-bonded technique (Carmeda $\mathrm{AB}$, Stockholm, Sweden) in which $18 \mathrm{mU} / \mathrm{cm}^{2}$ heparin molecules are coated on the membrane and circuit. The total amount of heparin used is $3,420 \mathrm{IU}$.

Thin-wall cannulas for blood drainage and delivery and polycarbonate connectors were not heparin-coated because of technical difficulties. The uncoated cannulas and connectors were dipped in saline with heparin $(1 \mathrm{IU} / \mathrm{ml})$ just before cannulation. The circuit and oxygenator were primed with a balanced salt solution, the total priming volume being approximately $130 \mathrm{ml}$. A heating pad was used to warm the trunk of the animal while hot air at $42{ }^{\circ} \mathrm{C}$ was blown over the entire ECMO system to maintain normothermia. No resuscitative efforts were made even if shock developed. No blood transfusions were given.

Oxygen $\left(\mathrm{O}_{2}\right)$ flow $(100 \%)$ was adjusted to maintain the gas flowblood flow ratio slightly above 1 . Once a stable bypass flow was achieved, the ventilator was readjusted to a minimal setting (peak pressure $12 \mathrm{~cm} \mathrm{H}_{2} \mathrm{O}$, end-expiratory pressure $3 \mathrm{~cm} \mathrm{H} \mathrm{H}_{2} \mathrm{O}$, respiratory rate $10 / \mathrm{min}$, inspired $\mathrm{O}_{2}$ fraction $30 \%$ ).
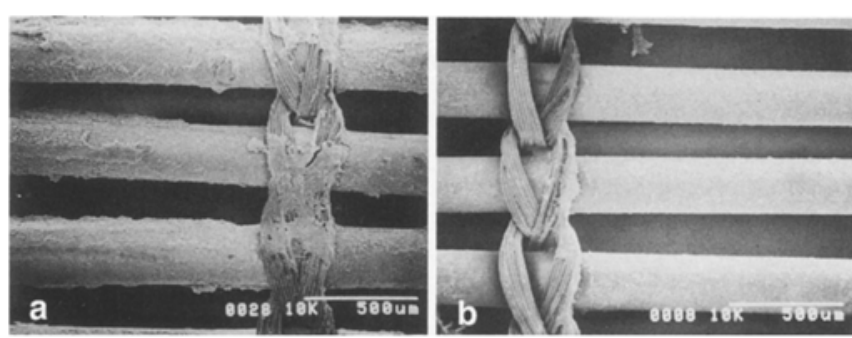

Fig. 2a-c Scanning electron photomicrographs in unsuccessful case: hollow fibers at a inlet, b central area, and c outlet of membrane oxygenator

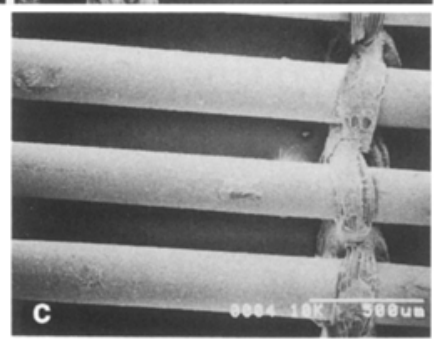

After $24 \mathrm{~h}$ ECMO, the animal was killed and the ECMO system was immediately removed. All blood remaining in the circuit was drained by gravity and gently washed out with balanced salt solution. The tubing and membrane oxygenator were examined for clot formation by scanning electron microscopy. The bioactivity of the heparin on the surface of this system was also examined by the same method used when the heparin was initially coated [1]. Microscopic examination of the lungs, liver, kidneys, and brain was performed.

The following coagulation parameters were measured: activated clotting time (ACT), blood heparin concentration, fibrinogen, antithrombin III (AT-III) activity, fibrinopeptide A (FPA), fibrinopeptide B B15-42 (FPB B15-42), D-dimer concentration, and platelets. ACT was measured before and every $2 \mathrm{~h}$ after ECMO began. The other parameters were measured at 0 (just after the cannulations), $1,6,12$, and $24 \mathrm{~h}$ after initiating ECMO. White blood cell (WBC), red blood cell (RBC), and activated complement 3,4 , and $5(\mathrm{C} 3 \mathrm{a}, \mathrm{C} 4 \mathrm{a}$, and $\mathrm{C} 5 \mathrm{a}$, respectively) counts were measured at the same time intervals as the other parameters.

Statistical comparisons were made by one-way analysis of variance (ANOVA) for repeated measures and Scheffe's test. An alpha error of less than 0.05 was considered significant.

\section{Results}

The ECMO outcomes are summarized in Table 1. ECMO was successfully performed throughout the experiment in four cases (cases 1 to 4); in one (case 5), after a successful 23-h run, it was discontinued because large blood clots formed at the oxygenator blood inlet. Concentrations of $\mathrm{O}_{2}$ and carbon dioxide $\left(\mathrm{CO}_{2}\right)$ of the blood downstream from the membrane oxygenator showed that oxygenation and

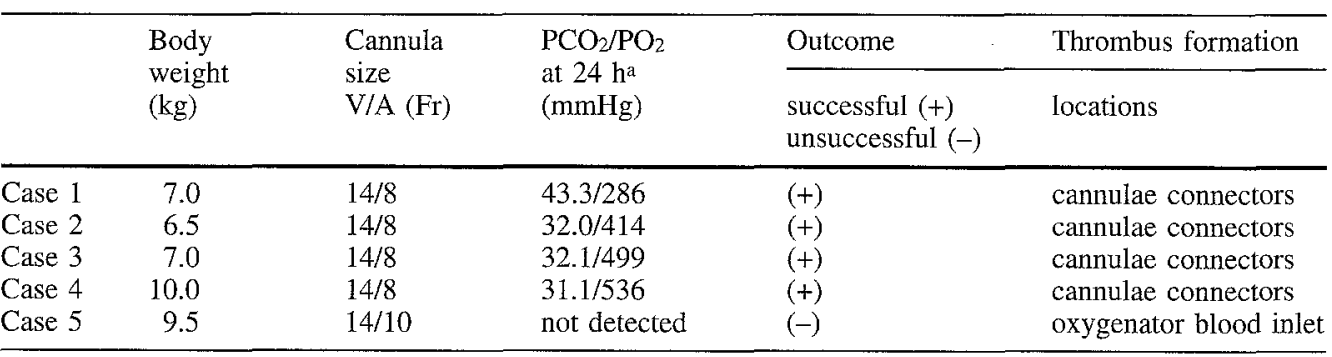

Table 1 Summary of ECMO outcomes ( $V$ venous, $A$ arterial)

\footnotetext{
a At outlet of membrane oxygenator
} 

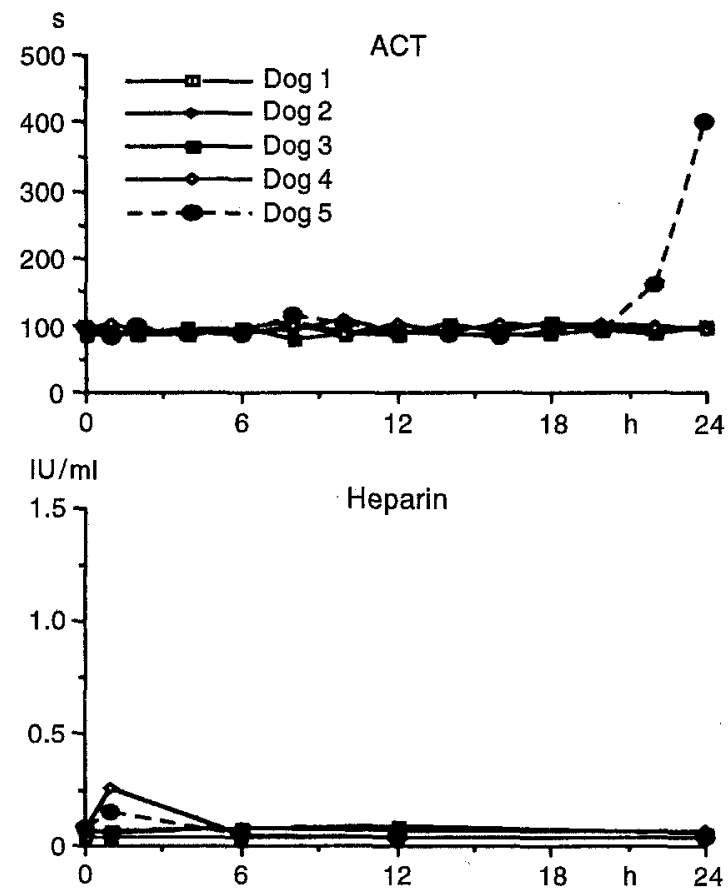

Fig. 3 Changes in activated clotting time (ACT) and heparin concentration

$\mathrm{CO}_{2}$ removal remained satisfactory throughout the experiment in successful cases.

Visible blood clots were seen on the heparin-coated surfaces only at the oxygenator inlet in the unsuccessful
Table 2 Blood parameters $(\mathrm{N}=5$, mean $\pm \mathrm{SD}, W B C$ white blood cells, $R B C$ red blood cells, $C a$ activated complements)

\begin{tabular}{|c|c|c|c|c|}
\hline & Control & $6 \mathrm{~h}$ & $12 \mathrm{~h}$ & $24 \mathrm{~h}$ \\
\hline $\begin{array}{l}\text { Platelets } \\
\qquad\left(10^{4} / \mathrm{mm}^{3}\right)\end{array}$ & $21.2 \pm 5.6$ & $13.3 \pm 2.9 \mathrm{a}$ & $7.2 \pm 1.0^{\mathrm{a}}$ & $6.4 \pm 1.2^{\mathrm{a}}$ \\
\hline $\begin{array}{l}\text { WBC } \\
\qquad\left(10^{4} / \mathrm{mm}^{3}\right)\end{array}$ & $1.06 \pm 0.44$ & $1.46 \pm 0.39$ & $1.57 \pm 0.64$ & $1.60 \pm 0.54$ \\
\hline $\begin{array}{l}\mathrm{RBC} \\
\qquad\left(10^{4} / \mathrm{mm}^{3}\right)\end{array}$ & $594 \pm 108$ & $548 \pm 35$ & $506 \pm 70$ & $518 \pm 137$ \\
\hline $\begin{array}{l}\text { C3a } \\
\quad(\mathrm{ng} / \mathrm{ml})\end{array}$ & $27.6 \pm 3.8$ & $33.0 \pm 5.0$ & $32.2 \pm 8.0$ & $31.8 \pm 10.1$ \\
\hline $\begin{array}{l}\mathrm{C} 4 \mathrm{a} \\
\quad(\mathrm{ng} / \mathrm{ml})\end{array}$ & $53.8 \pm 8.5$ & $59.2 \pm 15.7$ & $54.8 \pm 9.1$ & $59.4 \pm 12.5$ \\
\hline $\begin{array}{l}\text { C5a } \\
\quad(\mathrm{ng} / \mathrm{ml})\end{array}$ & $<10$ & $<10$ & $<10$ & $<10$ \\
\hline
\end{tabular}

case. Scanning electron microscopic photographs of the oxygenators in one of the successful cases are shown in Fig. 1. Only a few blood clots had formed around the hollow fibers of the oxygenator and its binding fibers. In contrast, Fig. 2 shows a photomicrograph from case 5 . There were visible blood clots inside and outside the nonheparin-coated cannulas in the carotid artery and jugular vein in all cases.

Changes in blood cell counts and $\mathrm{Ca}$ concentrations in all five cases are shown in Table 2. Platelets decreased from $6 \mathrm{~h}$ onward. Changes in WBC, $\mathrm{RBC}$, and $\mathrm{Ca}$ concentrations were not significant during ECMO. Figure 3 displays the changes in ACT and heparin concentrations. In the four successful cases ACT remained within a range of $80-100 \mathrm{~s}$
Fig. 4 Changes in coagulation parameters $(N=4$, mean $\pm S D$,

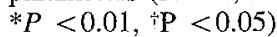
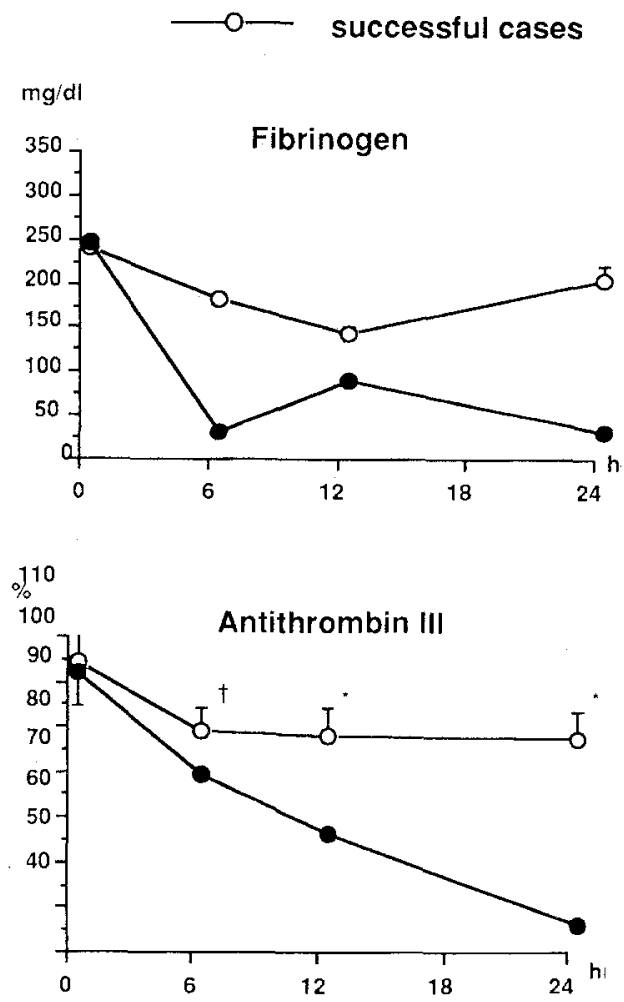
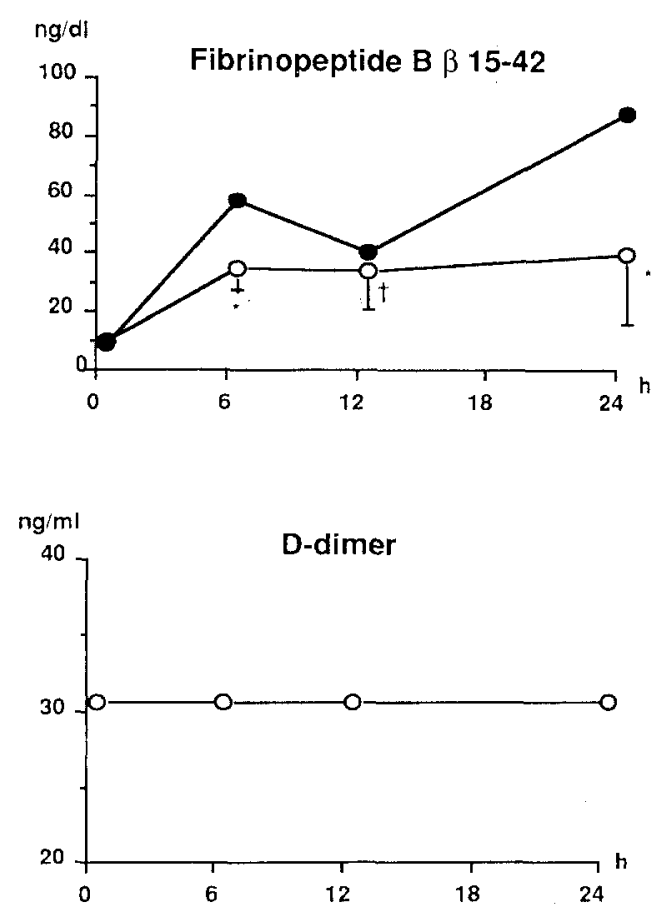
and heparin concentrations were low during the 24-h experiment. In case 5, ACT suddenly increased to $160 \mathrm{~s}$ at $22 \mathrm{~h}, 1 \mathrm{~h}$ prior to clot formation, and by $24 \mathrm{~h}$ had increased to over $400 \mathrm{~s}$, although the serum heparin concentration remained low. The bioactivity of heparin on the surface of the membrane examined in vitro remained the same after the 24-h experiment.

The changes in coagulation parameters are shown in Fig. 4. In the successful cases AT-III activity decreased significantly $6 \mathrm{~h}$ after ECMO began, but did not go below $75 \%$ at $24 \mathrm{~h}$. FPB $\beta 15-42$ increased significantly. Fibrinogen and FPA levels did not change during the entire 24-h perfusion period. D-dimer also did not change during the experiment. A decrease in fibrinogen and an increase in FPB $\beta 15-42$ were shown in the unsuccessful case from hour 6 until the completion of ECMO. Platelet count changes were similar to the other four cases. AT-III activity fell below $75 \%$ at $12 \mathrm{~h}$ and was $40 \%$ at $24 \mathrm{~h}$. Fibrinogen and AT-III appeared to be consumed. D-dimer did not change.

Histologic examination of the brain, kidney, spleen, and lungs showed no microscopic thrombi in any of the animals.

\section{Discussion}

The purpose of this study was to evaluate the feasibility of VA ECMO without systemic heparinization. Numerous attempts to diminish the total amount of systemic heparinization in order to avoid the tendency toward bleeding have been made since the $1970 \mathrm{~s}[8,15,18,21,24,26]$. The covalent-bonded heparin coating technique where partially degraded heparin has its covalent end-point attached to the surface of the ECMO circuit has been developed [16] for long-term ECMO. The favorable results obtained with this technique in adult patients with respiratory failure suggest the feasibility of long-term ECMO with minimal systemic heparinization $[4,13]$.

ECMO without systemic heparinization was successfully performed in four of five dogs for $24 \mathrm{~h}$ with this technique. Heparin from the coated system did not appear to leak into the bloodstream, as evidenced by the low levels of serum heparin concentration throughout the experiment. The bioactivity of heparin on the surface of the membrane oxygenator and the roller pump remained the same as on invitro examination in all cases. These findings suggest that the required amount of total systemic heparinization may be substantially reduced by use of the covalent-bonded technique in pediatric VA ECMO.

The coagulation parameters of the four successful and one unsuccessful cases in this study differed. The changes found in the four successful cases were consistent with previous heparin-free ECMO studies, although there has been some variance among investigators $[12,20]$. In this study, ACT remained within the normal range of 80-110 s. The decreases in platelet concentration observed were similar to previous reports performed either with or without systemic heparinization [9]. AT-III activity decreased, but remained within the physiologic range at $24 \mathrm{~h}$. Increases in FPB $\beta 15-42$ indicated hyperfibrinolysis; however, no secondary hyperfibrinolysis was detected, as was confirmed by the stable D-dimer values during the experiments. Small blood clots around the non-heparin-coated cannulas and connectors may account for the changes in coagulation parameters. It thus appears reasonable to conclude that heparin-free VA ECMO using a heparin-coated ECMO system during $24 \mathrm{~h}$ does not significantly affect the normal coagulation cascades of healthy dogs.

There was an unexpected prolongation of $\mathrm{ACT}$ to over $400 \mathrm{~s}$ prior to discontinuing ECMO in the unsuccessful case, even though heparin release was negligible. It is difficult to determine whether this coagulopathy resulted from the animal's individual characteristics or a specific mechanical problem with the particular ECMO circuit used. The sudden development of the abnormal ACT suggests that there is a certain risk in evaluating hemostatic status by ACT alone when systemic heparinization is totally avoided or markedly decreased.

Heparin concentration may be a useful parameter only during systemic heparinization when heparin is present in large amounts. The total amount of heparin used for surface coating in this method is too small to be detected by intermittent measurement of heparin concentration in the blood, and may thus not be a significant factor. A method of measuring heparin in the ACT assay has recently been developed to monitor heparin-independent alterations in coagulation functions [3], and may prove to be helpful.

Changes in coagulation parameters were measured to see whether total abolishment of systemic heparinization would promote disseminated intravascular coagulation (DIC). It is well known that DIC is common in sick neonates. Its etiologies are vast, and DIC may originate from maternal illness, birth complications, or underlying diseases such as sepsis.

Coagulation and fibrinolysis are kept in balance by the coordination of many factors, including endothelium and blood vessel vasoactivity. Rapid consumption of coagulation factors occurred in the unsuccessful case, with a large blood clot forming in the ECMO circuit. Secondary fibrinolysis did not follow, perhaps because blood clots did not form in vivo. The lack of histologic evidence of embolization is consistent with this speculation.

Several studies of changes in fibrinolysis inhibition under various conditions have been made. Elevation of plasminogen activator inhibitor (PAI) activity has been found in the acute respiratory distress syndrome $[7,14]$. Corrigan et al. suggested that newborns have lower levels of plasminogen (tPA) and tissue PAI relative to fibrinolytic inhibitors such as PAI-1 [6]. McVeen et al. [19] also reported that the levels of PAI- 1 activity and tPA antigen were significantly higher in newborns with severe respiratory failure, but were reduced during ECMO. These results suggest that sick newborns who require ECMO have a tendency toward hypercoagulopathies.

Animal studies on platelet function have shown that the surface heparinization technique does not improve platelet preservation [23]. This may indicate an earlier consumption 
of coagulation factors in animals than that seen in human adults. Careful monitoring of AT-III and FPB $\beta 15-42$ in addition to ACT would be useful for early diagnosis of a latent but ongoing coagulopathy during ECMO. Adequate supplements of AT-III and platelets may also be helpful in heparin-free ECMO.

In conclusion, the results of this study suggest that systemic heparinization can be substantially reduced by the use of a heparin-coated ECMO system. Total abolishment of heparin administration in VA ECMO remains to be further investigated.

\section{References}

1. Teien AN, Lie M (1977) Evaluation of an amidolytic heparin assay method: increased sensitivity by adding purified antithrombin III. Thromb Res 10: 399

2. Bartlett RH, Gazzaniga AB, Toomasian JM, Coran AG, Roloff D, Rucker R (1986) Extracorporeal membrane oxygenation in neonatal respiratory failure: 100 cases. Ann Surg 204: 336-341

3. Baugh RF, Deemar KA, Zimmermann JJ (1992) Heparinase in the activated clotting time assay: monitoring heparin-independent alterations in coagulation function. Anesth Analg 74: 201-205

4. Bindslev L (1988) Adult ECMO performed with surface-heparinized equipment. ASAIO Trans 34: 1009-1013

5. Bui KC, LaClair P, Vanderkerhove J, Bartlett RH (1991) ECMO in premature infants. Review of factors associated with mortality. ASAIO Trans 37: $54-59$

6. Corrigan JJ, Sleeth JJ, Jeter M, Lox CD (1989) Newborn fibrinolytic mechanism - component and plasminogen generator. Am J Hematol 32: 237-278

7. Dirschstein W, Heene DL (1985) Fibrinolysis inhibition in acute respiratory distress syndrome. Scand J Clin Lab Invest 45: 87-94

8. Fletcher JR, McKee AE, Mills M, Snyder KC, Herman CM (1976) Twenty-four hour membrane oxygenation in dogs without anticoagulation. Surgery $80: 214-223$

9. Fong SW, Burns NE, Williams G, Woldanski C, Gazzaniga AB, Bartlett RH (1974) Changes in coagulation and platelet function during prolonged extracorporeal circulation (ECC) in sheep and man. ASAIO Trans 20: 239-247

10. Frenckner B, Ehren H, Palmer K (1991) Patient complications during extracorporeal membrane oxygenation (ECMO). Eur J Pediatr Surg 1: 339-342

11. Klein MD, Shaheen KW, Whittlesey GC, Pinsky WW, Arciniegas E (1990) Extracorporeal membrane oxygenation for the circulatory support of children after repair of congenital heart disease. J Thorac Cardiovasc Surg 100: 498-505
12. Koul B, Vesterqvist Ole, Egberg N, Steen S (1992) Twenty-fourhour heparin-free veno-right ventricular ECMO: an experimental study. Ann Thorac Surg 53: 1046-1051

13. Koul B, Wetterberg T, Ohqvist G, Olsson P (1991) Veno-venous extracorporeal membrane oxygenation with a heparin-coated system in adult respiratory distress syndrome. Scand J Thorac Cardiovasc Surg 25: 199-206

14. Kruithof EKO, Gudinchet A, Bachman F (1988) Plasminogen activator inhibitor 1 and plasminogen activator inhibitor 2 in various disease states. Thromb Haemost 59: 7-12

15. Kundu SK, Salley SO, Whittlesey GC, Klein MD (1989) Extracorporeal membrane oxygenation without anticoagulation: a study using quantitative scanning electron microscopy. J Lab Clin Med 114: $58-62$

16. Larm O, Larsson R, Olsson P (1983) A new non-thrombogenic surface prepared by selective covalent binding of heparin via a modified reducing terminal residue. Biomater Med Devices Artif Organs 11: 161-173

17. Levy FH, O'Rourke PP, Crone RK (1992) Extracorporeal membrane oxygenation. Anesth Analg 75: $1053-1062$

18. Ludwig KS, Turina M (1989) Cardiopulmonary bypass without systemic heparinization. J Thorac Cardiovasc Surg 98: 386-396

19. Mc Veen RV, Lorch V, Carroll RC, Goldberg L, Keszler M, Podlasek S, Stewart DL (1991) Changes in fibrinolytic factors in newborns during extracorporeal membrane oxygenation (ECMO) [letter]. Am J Hematol 38: 254-255

20. Mottaghy K, Oedekoven B, Pöppel K, Bruchmöller K, Kovacs B, Spahn A, Geisen C (1989) Heparin free long-term extracorporeal circulation using bioactive surfaces. ASAIO Trans 35: 635-637

21. Murphy TL, Walker FJ, Taylor III FB, Beller-Todd B, Archer LT, Sofer SS, Hinshaw LB (1980) Endogenous anticoagulation during extracorporeal perfusion: generation of a heparin-like inhibitor. Am J Physiol 239: 742-750

22. del Nido PJ, Dalton HJ, Thompson AE, Siewers RD (1992) Extracorporeal membrane oxygenator rescue in children during cardiac arrest after cardiac surgery. Circulation 86: 300-304

23. Palatianos GM, Dewanjee MK, Kapadvanjwala M, Novak S, Sfakianakis GN, Kaiser GA (1990) Cardiopulmonary bypass with a surface-heparinized extracorporeal perfusion system. ASAIO Trans 36: $476-479$

24. Segesser LK, Lachat M, Gallino A, Leskosek B, Garcia E, Hänseler E, Felten A, Turina M (1990) Performance characteristics of centrifugal pumps with heparin surface coating. Thorac Cardiovasc Surgeon 38: 224-228

25. Watson JW, Brown DM, Lally KP, Null D, Clark R (1990) Complications of extracorporeal membrane oxygenation in neonates. South Med J 83: 1262-1265

26. Whittlesey GC, Drucker DEM, Salley SO, Smith HG, Kundu SK, Palder SB, Klein MD (1991) ECMO without heparin: laboratory and clinical experience. J Pediatr Surg 26: 320-325 